\title{
Color duplex ultrasonography findings of temporal arteries in a case of giant cell arteritis: role in diagnosis and follow-up
}

This article was published in the following Dove Press journal:

Open Access Rheumatology: Research and Reviews

15 March 2017

Number of times this article has been viewed

\author{
Antonella Laria \\ Alfredo Lurati \\ Magda Scarpellini \\ Fornaroli Hospital, Rheumatology \\ Unit, Magenta, Italy
}

\begin{abstract}
Giant cell arteritis (GCA) is a systemic autoimmune disease that affects medium- and large-sized arteries. The diagnostic gold standard is the temporal artery biopsy, but it has limited sensitivity and some difficulties in reproducibility. Color duplex ultrasonography is a noninvasive, reproducible, and inexpensive method for diagnosis of temporal arteries involvement (temporal arteritis [TA]) in GCA with high sensitivity and specificity. We present the ultrasound findings at baseline and during follow-up in a case of TA in a patient with GCA.
\end{abstract}

Keywords: color duplex ultrasonography, temporal arteries, halo sign, temporal arteritis, GCA

\section{Introduction}

Giant cell arteritis (GCA) is a medium/large vessels vasculitis that predominantly affects temporal arteries (temporal arteritis [TA]). It represents the most common form of systemic vasculitis in adults. ${ }^{1,2}$ The temporal artery biopsy (TAB) is the latest diagnostic gold standard but it suffers a low sensitivity because of the segmental nature of the vasculitis process in TA and a negative biopsy does not rule out the diagnosis. As stated by several studies, the ultrasonography has a key role in the diagnosis and follow-up of TA. The ultrasonographic evaluation can assess stenosis, occlusions, and Doppler flow abnormalities of temporal artery segments and the dark halo around the

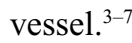

We present a case of TA with pathologic findings in color duplex ultrasonography (CDU) that disappeared after 7 days of steroid treatment.

\section{Case report}

On February 24, 2016, a 77 year old male was admitted to our Rheumatology Unit for a frontal temporal non-steroidal anti-inflammatory drugs resistant headache. The patient provided his written consent to have his data used for this case report. He had no scalp tenderness, jaw claudication, or systemic manifestations (fever, weight loss, anorexia, and malaise). Patient had no myalgia or ocular symptoms (such as monocular, binocular vision loss, diplopia, or ocular pain). The temporal arteries were painful and thickened. The acute-phase reactants were raised with an erythrocyte sedimentation rate value of $71 \mathrm{~mm} / \mathrm{h}$ (normal range $0-10$ ) and a C-reactive protein value of $11.1 \mathrm{mg} / \mathrm{dL}$ (normal range 0-5). A normocytic anemia (hemoglobin $12.7 \mathrm{~g} / \mathrm{dL}$, normal range of 14-18) and an abnormal liver function with raised a1 and a2 globulins on serum electrophoresis were present. Laboratory tests did not show thrombocytosis. Brightness-mode (B-mode) 
ultrasound of shoulders did not show ultrasound subacromial/ subdeltoid bursitis or long head biceps tenosynovitis. The CDU assessment was performed by an experienced rheumatologist, using an Esaote MyLab Seven ultrasound system with a highresolution linear probe VFX 18-6 MHz (Esaote SpA, Genoa, Italy). Doppler frequency was $>6.5 \mathrm{MHz}$, dynamic range between 45 and $50 \mathrm{~dB}$, other system settings were set to meet the high standards defined in the literature. ${ }^{8,9}$ Examination of the superficial temporal arteries (the common, frontal, and parietal branches) was performed in longitudinal and transverse planes. We found a hypoechogenic halo of the left temporal artery $>0.5 \mathrm{~mm}$ in thickness (Figure 1A and B). Moreover, left temporal artery Doppler signal showed the presence of turbulent flow (Figure 2).

The follow-up CDU examination was performed 7 days later. On clinical, laboratory, and ultrasound findings, we

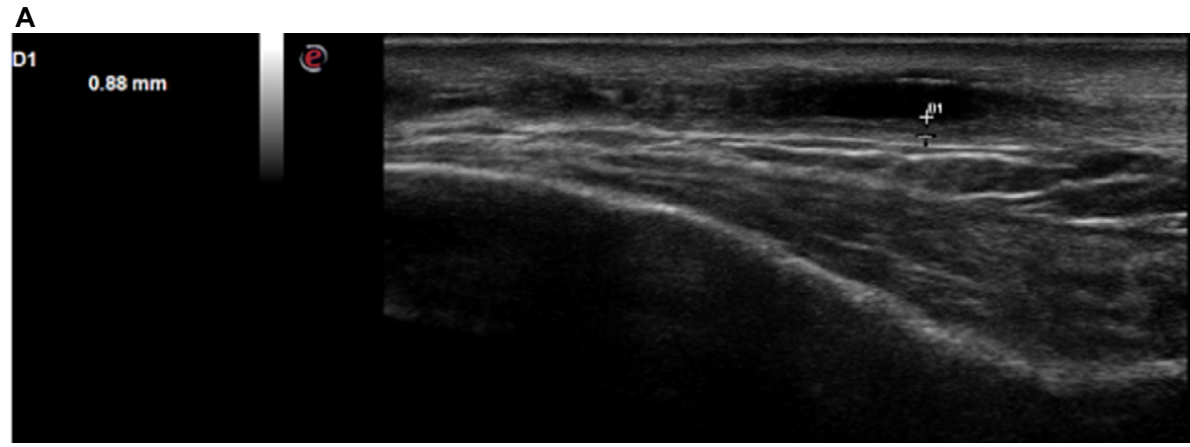

B

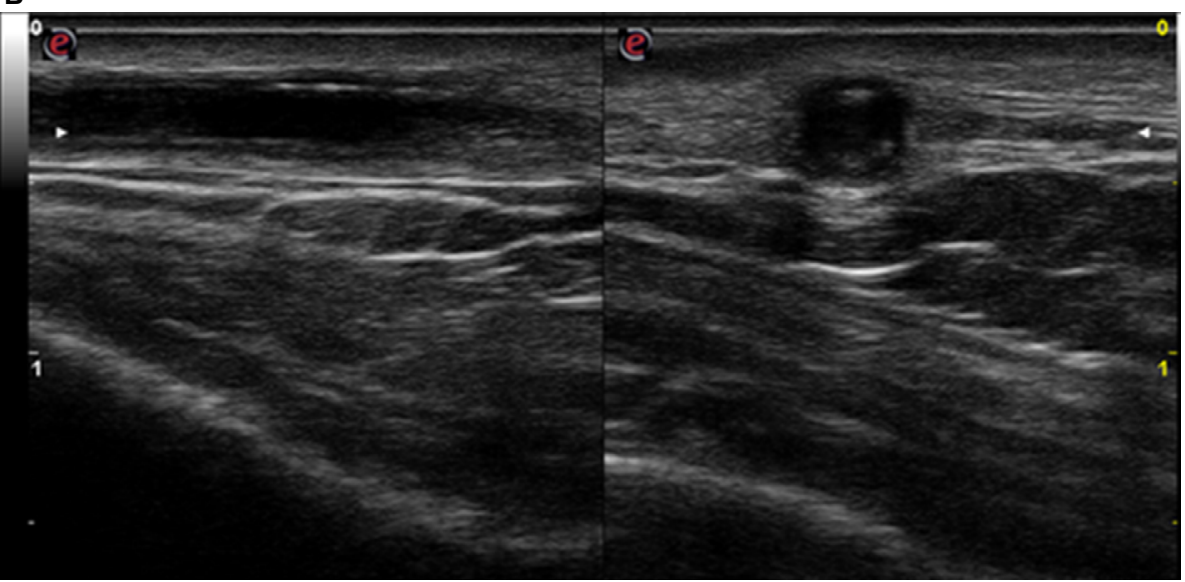

Figure I (A) Before treatment: left temporal artery ultrasonography features before steroid therapy showed a hypoechogenic halo of the temporal artery $>0.5 \mathrm{~mm}$ in thickness. (B) Before treatment: left temporal artery ultrasonography features before steroid therapy showed a hypoechogenic halo of the temporal artery in longitudinal (left) and transverse (right) view (B-mode ultrasound).

Abbreviation: B-mode, brightness-mode.

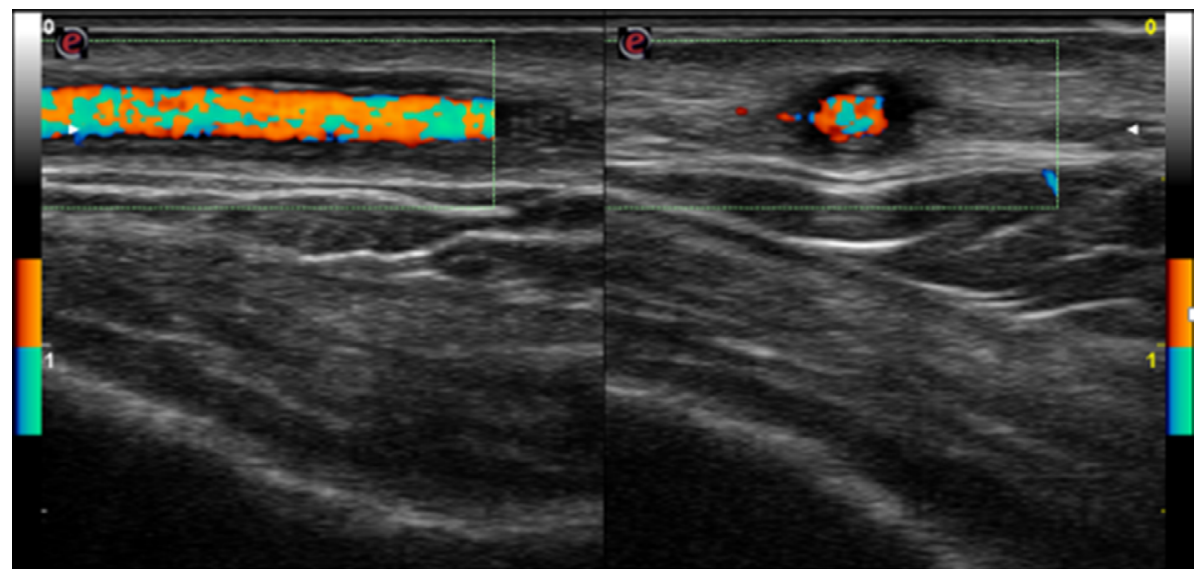

Figure 2 Before treatment, left temporal artery color duplex ultrasonography features before steroid therapy showed a hypoechogenic halo of the temporal artery and the presence of turbulent flow; longitudinal (left) and transverse (right) view. 
formulated the diagnosis of GCA and we immediately started therapy to avoid retinal damage with blindness. We administered oral prednisone $1 \mathrm{mg} / \mathrm{kg}$ and introduced low-dose aspirin.
As seen in Figure 3, the halo sign and the turbulent flow disappeared (left temporal artery). The right temporal artery showed a marked reduction of halo sign, as seen in Figure 4A (before treatment) and B (after 7 days of treatment). TAB

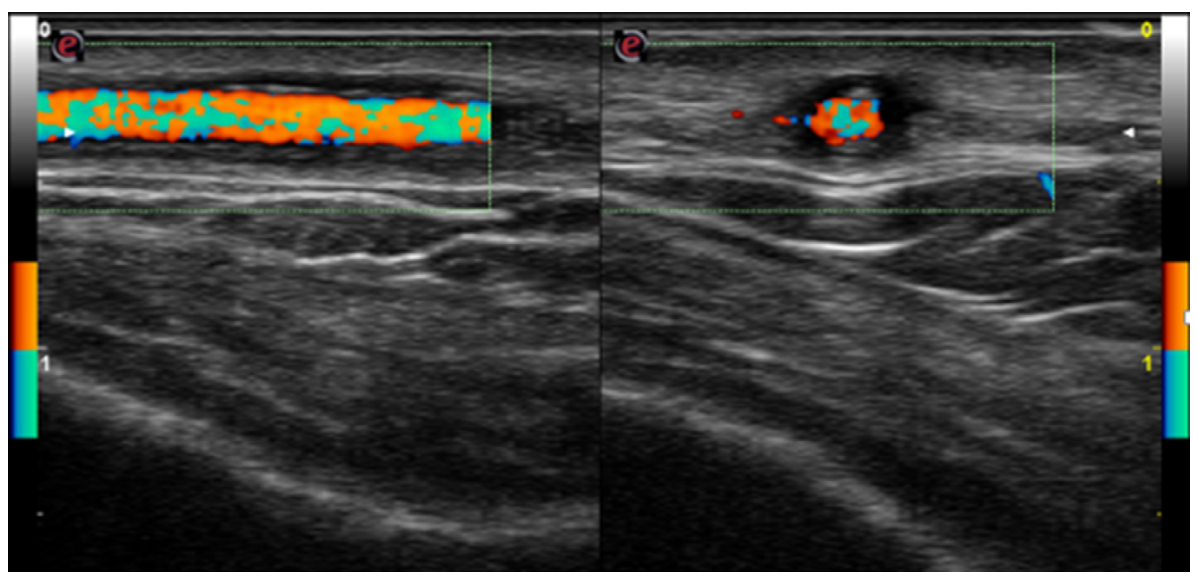

Figure 3 Posttreatment left temporal artery color duplex ultrasonography, transverse (left) and longitudinal (right) view, showed disappearance of hypoechogenic halo of the temporal artery and of turbulent flow; longitudinal and transverse view, respectively.
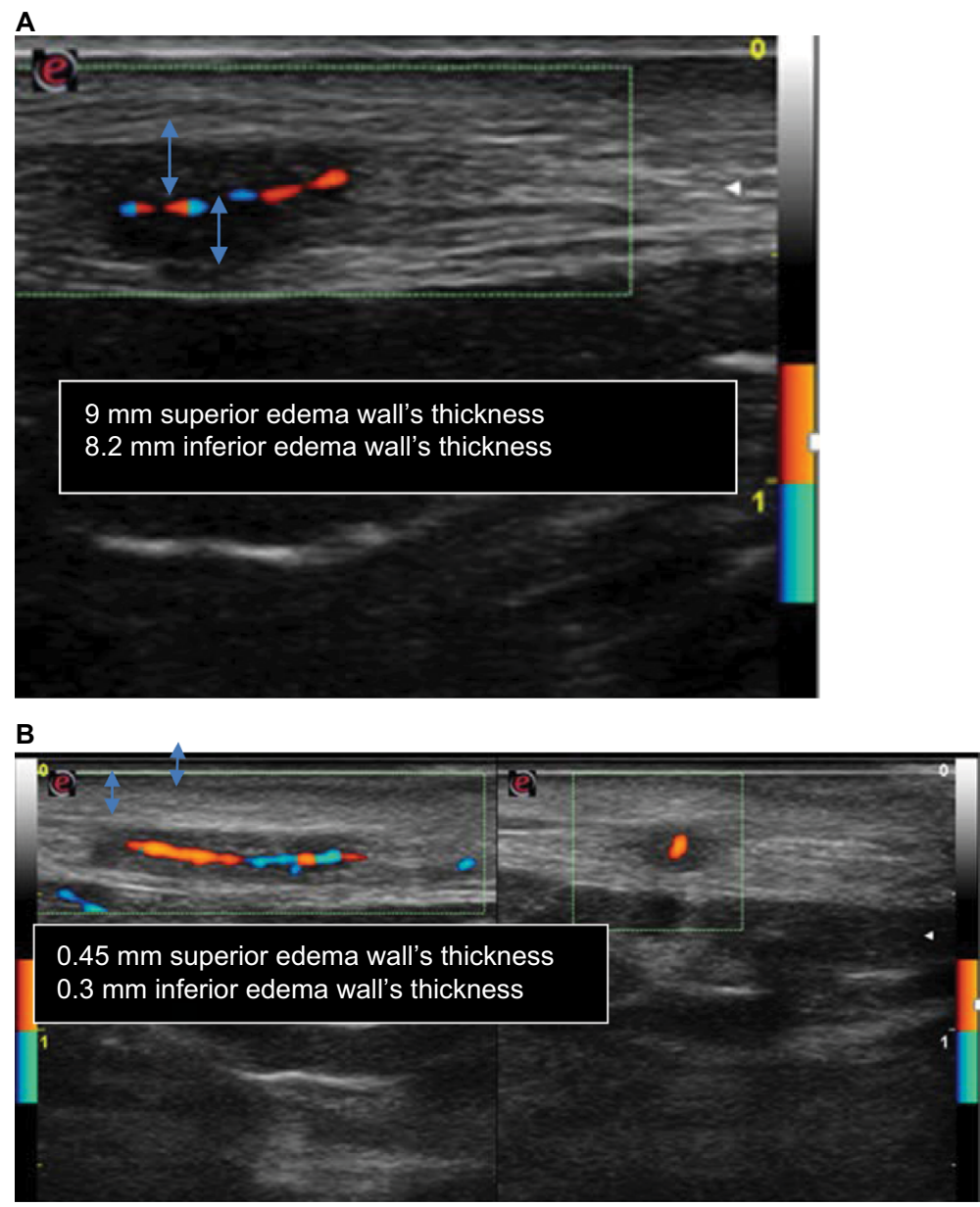

Figure 4 (A) In the left side: before treatment, longitudinal view of right temporal artery CDU features before steroid therapy showed a hypoechogenic halo of the temporal artery and the presence of turbulent flow and weak flow because of the presence of halo sign corresponding to edema of artery wall (measured $\sim 9$ mm superior edema wall's thickness and $8.2 \mathrm{~mm}$ inferior edema wall's thickness). (B) Posttreatment, longitudinal and transverse view, respectively, of right temporal artery CDU showed reduction of halo sign and turbulent flow and a stronger flow than before treatment that corresponds to a significant reduction of edema of artery wall (measured $\sim 0.45 \mathrm{~mm}$ superior edema wall's thickness and $0.3 \mathrm{~mm}$ inferior edema wall's thickness).

Abbreviation: CDU, color duplex ultrasonography. 
was not performed because of difficulties in reproducibility and because of the presence of bilateral halo sign that has a high specificity in the diagnosis of TA, suggesting that TAB can be spared by CDUs.

\section{Discussion}

GCA, first described by Horton et $\mathrm{al},{ }^{10}$ is a systemic immunemediated vasculitis affecting medium- and large-sized arteries. ${ }^{9-11}$ The pathophysiology of GCA includes both innate and adaptative immune response dysregulation. The characteristic histologic lesion is a granulomatous inflammation nearby the internal elastic lamina. ${ }^{11}$ The inflammatory infiltrate (constituted of lymphocytes, macrophages eventually as multinucleated giant cells and fibroblasts) can affect all the three arterial layers. Chew et al found an association between the presence of giant cells and visual loss. ${ }^{12}$ The clinical manifestations of GCA are related to both systemic inflammation (malaise, fever, and weight loss) and vascular insufficiency/ischemia (headache, scalp tenderness, jaw claudication, and monocular or binocular vision loss). ${ }^{13}$ The serological findings are representative of an acute-phase response with high levels of erythrocyte sedimentation rate, C-reactive protein, and anemia. ${ }^{14,15}$ Arteritic anterior ischemic optic neuropathy is the most common ophthalmologic manifestation and typically presents with sudden, painless, and profound unilateral or bilateral vision loss (78\%-99\%). ${ }^{11}$ The mainstay of management includes high-dose corticosteroids, and additional cytotoxic drugs, antitumor necrosis factor monoclonal antibody, and antiplatelet aggregation therapy may be used. The goal of treatment is to prevent ischemic damage and halt progression of visual loss in the affected eye and prevent involvement of the fellow eye. Till date, TAB remains the gold standard diagnostic test, with a temporal artery specimen of at least $2 \mathrm{~cm}$ should be sought. If a TAB is negative and clinical suspicion remains high, biopsy on the contralateral side should be considered, providing a positive specimen in $4 \%-15 \%$ of patients when the first biopsy is negative. ${ }^{16,17}$ Various imaging techniques have been recommended for diagnosis and follow-up of GCA and GCA-related complications. CDU can visualize the restricted arterial flow, wall edema, appearing as hypoechoic halos immediately adjacent to the arterial wall, with a sensitivity and specificity of $69 \%$ and $82 \%$, respectively. ${ }^{18,19}$ Salvarani et al reported that only halos $>1 \mathrm{~mm}$ in thickness increased the probability of positive result of TA. ${ }^{20}$ On the contrary, Habib et al showed that smaller halos of $\geq 0.5 \mathrm{~mm}$ thickness can predict TA, a finding reported by others. ${ }^{7,21,22}$ In addition, bilateral halo sign yields a sensitivity of $37 \%$ and specificity of $100 \%$ in the diagnosis of TA, suggesting that the presence of bilateral halo sign in patients with clinically suspected
TA can replace TAB in their final diagnosis, a suggestion reported by other studies. ${ }^{7,20}$ The goals of GCA treatment are to avoid visual loss in the affected eye. Glucocorticoids exert multiple anti-inflammatory effects. ${ }^{7,22}$ There is still no consensus on the correct dose or route of administration of corticosteroids. The starting steroid treatment dosage ranges between $1 \mathrm{mg} / \mathrm{kg}$ and $1 \mathrm{~g} /$ day for a minimum of 3 days. ${ }^{11,19}$ The clinical and laboratoristic responses are usually rapid within 24-72 h after initiation of therapy. Regardless of the initial starting dose, most patients remain on oral prednisone $1 \mathrm{mg} / \mathrm{kg}$ for a minimum of 4 weeks after which time steroids should be tapered on the basis of symptoms and serial monitoring of inflammatory markers. Other drugs, such as methotrexate, azathioprine, cyclophosphamide, dapsone, and cyclosporine, have been used as adjuvant steroid-sparing therapy. Antitumor necrosis factor monoclonal antibody (eg, infliximab) has been proposed as either first-line therapy or a steroid-sparing agent in GCA. ${ }^{23-26}$ Antiplatelet aggregation therapy with low-dose aspirin before or at the time of diagnosis has been associated with a lower risk for developing acute vision loss and cerebrovascular accidents. ${ }^{27,28}$ In our case, steroids induced early disappearance of the halo sign, leading to the normalization of CDU, after 7 days from beginning the therapy. We can conclude that CDU has many advantages: first of all, it has an easy reproducibility (more reproducible than high-resolution computed tomography/positron emission tomography-computed tomography/magnetic resonance imaging) because of bedside and radiation-free hallmarks; it is sensitive to both cranial and extracranial disease. CDU is not only useful in helping in the diagnosis of TA but also useful in following up of patients after initiation of therapy. However, ultrasonography is highly operator and equipment dependent, and it is unable to easily visualize thoracic aorta. CDU has high sensitivity and specificity when it is performed by an experienced operator; however, in literature, there are very heterogeneous results regarding this technique, with test sensitivities ranging from $10 \%$ to $87 \% .{ }^{29-33}$ Hence, larger studies focusing on technical standardization of equipment, probe settings, image acquisition, and examination are required.

\section{Disclosure}

The authors report no conflicts of interest in this work.

\section{References}

1. Hunder GG. The early history of giant cell arteritis and polymyalgia rheumatica. First descriptions to 1970. Mayo Clin Proc. 2006;81(8):1071-1083.

2. Hellmann DB. Giant cell arteritis and polymyalgia rheumatica. In: Imboden JB, Hellmann DB, Stone JH, editors. Current Rheumatology Diagnosis and Treatment. New York, NY: Mc Graw Hill; 2004:235-241. 
3. Weyand CM, Goronzy JJ. Giant-cell arteritis and polymalgia rheumatica. Ann Intern Med. 2003;139(6):505-515.

4. Hall JK, Volpe NJ, Galetta SL, Liu GT, Syed NA, Balcer LJ. The role of unilateral temporal artery biopsy. Ophthalmology. 2003;110(3): 543-548; discussion 548.

5. Ball EL, Walsh SR, Tang TY, Gohil R, Clarke JM. Role of ultrasonography in the diagnosis of temporal arteritis. Br J Surg. 2010;97(12):1765-1771.

6. Nesher G, Shemesh D, Mates M, Sonnenblick M, Abrmowitz HB. The predictive value of the halo sign in color Doppler ultrasonography of the temporal arteries for diagnosing giant cell arteritis. $J$ Rheumatol. 2002;29(6):1224-1226.

7. Karahaliou M, Vaiopoulos G, Papaspyrou S, Kankis MA, Revenas K, Sfikakis PP. Colour duplex sonography of temporal arteries before decision for biopsy: a prospective study in 55 patients with suspected giant cell arteritis. Arthritis Res Ther. 2006;8(4):R116.

8. Schmidt WA. Doppler ultrasonography in the diagnosis of giant cell arteritis. Clin Exp Rheumatol. 2000;18(4 Suppl 20):S40-S42.

9. Schmidt WA, Gromnica-Ihle E. What is the best approach to diagnosing large-vessel vasculitis? Best Pract Res Clin Rheumatol. 2005;19(2) 223-242.

10. Horton BT, Magath BT, Brown GE. Arteritis of temporal vessels: report of 7 cases. Proc Staff Meet Mayo Clin. 1937;12:548-553.

11. Jennings GH. Arteritis of the temporal vessels. Lancet. 1938;1:424.

12. Chew SS, Kerr NM, Danesh-Meyer HV. Giant cell arteritis. J Clin Neurosci. 2009;16(10):1263-1268.

13. Chatelain D, Duhaut P, Schmidt J, et al; Groupe de Recherche sur 1'Artérite à Cellules Géantes. Pathological features of temporal arteries in patients with giant cell arteritis presenting with permanent visual loss. Ann Rheum Dis. 2009;68(1):84-88.

14. Stone JH, Papaliodis GN, Dunbar MR, Stone JR. Case records of the Massachusetts General Hospital. Case 4-2010. A 53-year-old man with arthralgias, oral ulcers, vision loss, and vocal-cord paralysis. $N$ Engl $J$ Med. 2010;362(6):537-546.

15. Hunder GG, Bloch DA, Michel BA, et al. The American College of Rheumatology 1990 criteria for the classification of giant cell arteritis. Arthritis Rheum. 1990;33(8):1122-1128.

16. Dasgupta B, Borg FA, Hassan N, et al; BSR and BHPR Standards, Guidelines and Audit Working Group. BSR and BHPR guidelines for the management of giant cell arteritis. Rheumatology (Oxford). 2010;49(8): 1594-1597.

17. Breuer GS, Nesher G, Nesher R. Rate of discordant findings in bilateral temporal artery biopsy to diagnose giant cell arteritis. $J$ Rheumatol. 2009;36(4):794-796

18. Danesh-Meyer HV, Savino PJ, Eagle RC Jr, Kubis KC, Sergott RC. Low diagnostic yield with second biopsies in suspected giant cell arteritis. J Neuroophthalmol. 2000;20(3):213-215.

19. Carroll SC, Gaskin BJ, Danesh-Meyer HV. Giant cell arteritis. Clin Exp Ophthalmol. 2006;34(2):159-173
20. Salvarani C, Silingardi M, Ghirarduzzi A, et al. Is duplex ultrasonography useful for the diagnosis of giant-cell arteritis? Ann Intern Med. 2002;137(4):232-238

21. Habib HM, Essa AA, Hassan AA. Color duplex ultrasonography of temporal arteries: role in diagnosis and follow-up of suspected cases of temporal arteritis. Clin Rheumatol. 2012;31(2):231-237.

22. Reinhard M, Schmidt D, Hetzel A. Color coded sonography in suspected temporal arteritis - experience after 83 cases. Rheumatol Int. 2004;24(6):340-346.

23. Hoffman GS, Cid MC, Hellmann DB, et al; International Network for the Study of Systemic Vasculitides. A multicenter, randomized, doubleblind, placebo-controlled trial of adjuvant methotrexate treatment for giant cell arteritis. Arthritis Rheum. 2002;46(5):1309-1318.

24. Spiera RF, Mitnick HJ, Kupersmith M, et al. A prospective, doubleblind, randomized, placebo controlled trial of methotrexate in the treatment of giant cell arteritis (GCA). Clin Exp Rheumatol. 2001;19(5): 495-501.

25. Devauchelle-Pensec V, Jousse S, Destombe C, Saraux A. Epidemiology, imaging, and treatment of giant cell arteritis. Joint Bone Spine. 2008;75(3):267-272.

26. Hoffman GS, Cid MC, Rendt-Zagar KE, et al; Infliximab-GCA Study Group. Infliximab for maintenance of glucocorticosteroid-induced remission of giant cell arteritis: a randomized trial. Ann Intern Med. 2007;146(9):621-630.

27. Nesher G, Berkun Y, Mates M, Baras M, Rubinow A, Sonnenblick M. Low-dose aspirin and prevention of cranial ischemic complications in giant cell arteritis. Arthritis Rheum. 2004;50(4):1332-2137.

28. Lee MS, Smith SD, Galor A, Hoffman GS. Antiplatelet and anticoagulant therapy in patients with giant cell arteritis. Arthritis Rheum. 2006;54(10):3306-3309.

29. Diamantopoulos AP, Haugeberg G, Hetland H, Soldal DM, Bie R, Myklebust G. Diagnostic value of color Doppler ultrasonography of temporal arteries and large vessels in giant cell arteritis: a consecutive case series. Arthritis Care Res (Hoboken). 2014;66(1):113-119.

30. Maldini C, Depinay-Dhellemmes C, Tra TT, et al. Limited value of temporal artery ultrasonography examinations for diagnosis of giant cell arteritis: analysis of 77 subjects. J Rheumatol. 2010;37(11): 2326-2330.

31. Schmidt WA, Kraft HE, Vorpahl K, Volker L, Gromnica-Ihle EJ. Color duplex ultrasonography in the diagnosis of temporal arteritis. $N$ Engl $J$ Med. 1997;337(19):1336-1342.

32. Karassa FB, Matsagas MI, Schmidt WA, Ioannidis JP. Meta-analysis: test performance of ultrasonography for giant-cell arteritis. Ann Intern Med. 2005;142(5):359-369.

33. Arida A, Kyprianou M, Kanakis M, Sfikakis PP. The diagnostic value of ultrasonography-derived edema of the temporal artery wall in giant cell arteritis: a second meta-analysis. BMC Musculoskelet Disord. 2010;11:44.
Open Access Rheumatology: Research and Reviews

\section{Publish your work in this journal}

Open Access Rheumatology: Research and Reviews is an international, peerreviewed, open access journal publishing original research, reports, editorials, reviews and commentaries on all aspects of clinical and experimental rheumatology in the clinic and laboratory including the following topics: Pathology, pathophysiology of rheumatological diseases; Investigation, treatment and management of rheumatological diseases; Clinical trials and novel pharmacologi$\mathrm{cal}$ approaches for the treatment of rheumatological disorders. The manuscript management system is completely online and includes a very quick and fair peer-review system, which is all easy to use. Visit http://www.dovepress.com testimonials.php to read real quotes from published authors. 